\title{
Representaciones sociales de la ética empresarial en Venezuela
}

\author{
Leslie Borjas de Xena \\ Dilia Monasterio de Márquez
}

\begin{abstract}
Social representation theory from authors like Moscovici and Jodelet constitutes a critical proposal to analyze social reality in its complexity. This article adopts this theory to study the representations of business ethics as a social process by a Venezuelan managerial community, employing a methodology that incorporates an interpretative approach and a complementary method. The social representations revealed were: responsibility, solidarity and honesty. The results showed a conceptualization of business ethics that converges with social responsibility as corporative and communitarian.
\end{abstract}

\section{Introducción}

La conceptualización de la ética empresarial es asumida desde diferentes perspectivas. Verstraeten (2000) la concibe como una investigación del comportamiento de los empresarios, gerentes y empleados, y de las consecuencias de los comportamientos éticos o no éticos de las empresas. García Marza (2004) señala que la ética empresarial se origina en los patrones presentes en el mundo debido a la globalización, los nuevos valores y percepciones que definen el papel de la empresa en la sociedad. Este autor sostiene que la ética empresarial que se ocupa de las "condiciones de posibilidad de la credibilidad social de la empresa y por tanto, de la confianza depositada en la empresa por parte de todos aquellos grupos que forman parte o están afectados por su actividad" (2004: 23). Cortina (2005), a su vez, se centra en la concepción de la empresa como una organización económica y como una institución social.

La ética empresarial es un área de la ética aplicada que, como tal, exige no sólo el aporte de filósofos, teólogos, psicólogos y sociólogos, sino también de expertos en las ciencias económico-administrativas. Para Martínez (2007), este 
campo exige un nuevo hombre más responsable, capaz de hacer juicios de valor, de tomar decisiones y de trabajar en equipos multidisciplinarios, multiétnicos y multinacionales. En la literatura se presentan los enfoques provenientes de Norteamérica como la principal fuente de conocimiento en esta área y con la mayor influencia sobre las diferentes tendencias. Por otra parte, Spence (2000) señala que la corriente emergente europea estudia los problemas de la ética empresarial sin apelar tanto a la legalidad para resolverlos, proporcionándole un mayor peso a los valores sociales y una mayor confianza a la autorregulación

En Venezuela, la ética empresarial ha sido estudiada como un discurso normativo, el cual se desarrolla principalmente a partir del año 2000 con estudios que buscan la comprensión de su realidad. Ferrer, Clemenza y Vázquez (2000), en un estudio realizado sobre la ética en las industrias metalúrgicas y metalmecánicas de la región zuliana, concluyen que estas empresas se desarticularon internamente de forma paulatina y crearon condiciones de coexistencia a nivel del sector en su conjunto. Posteriormetne cayeron en un estado de supervivencia temporal, ocasionada, entre otros, por factores de orden político-económico tales como el proceso de apertura de los mercados petroleros. Este proceso enfrentó dos o más sistemas de convivencia antagónicos, formados por empresas con capacidad para establecer tímidamente su perspectiva del negocio y empresas extranjeras con grandes capitales dispuestas a invertir sus recursos, mas no a concertar con creencias y valores de las regiones involucradas.

En Venezuela, un elemento a tener en cuenta asociado a la ética empresarial es la corrupción. En un estudio de tipo correlacional, Monasterios (2003) comprobó que en las instituciones venezolanas existen una variedad de factores condicionantes de comportamientos corruptos. Existen factores de carácter interno, vinculados a la estructura de cada organización, y factores externos que se encuentran asociados a las condiciones socio-culturales propias del país. Ambos factores coexisten y determinan la presencia de modalidades tales como: uso indebido de recursos en la organización, falsificación de documentos, usurpación de la autoridad y de títulos y honores, aceptación de sobornos, lavado de activos y designación de empleos o contratos en función de algún interés particular. Por otra parte, en la descripción y correlación de los factores y modalidades de hechos de corrupción en las organizaciones venezolanas hechas por este autor se puede observar la estructura de oportunidades presentes en el sector público. De esta forma, el estudio cubre casi en su totalidad las formas, tipos y grados de la corrupción, lo cual permite afirmar que todos los elementos estudiados contribuyen a la aparición de la corrupción. Este fenómeno, además, está relacionado con los patrones éticos del funcionario público. Sin embargo, existen otros rasgos en la práctica diaria de los profesionales en el sector que 
reflejan una tendencia de los patrones éticos hacia escalas negativas. Njaim (2008) a su vez plantea que la corrupción tiene multiplicidad de objetivos que se pueden vislumbrar en la forma de organizaciones políticas de la sociedad y que "es una realidad, con la que hay que contar como ingrediente de cualquier sistema político" (p.184).

Borjas y Rosales (2005) han presentado una experiencia enmarcada en el área de responsabilidad social, estudio realizado en una empresa productora de ron en la comunidad de Santa Teresa (Estado Miranda, Venezuela). Esta empresa ha reportado grandes beneficios no sólo en materia de ética empresarial - su modelo ha sido seguido en otros lugares por otras organizaciones - sino también en bienestar para la comunidad donde se encuentra, como por ejemplo la reducción de la delincuencia y el apoyo a la creación de nuevas fuentes de trabajo.

Martínez (2007), en un estudio realizado entre funcionarios públicos del sector salud venezolano, pone de manifiesto la tendencia que tienen los encuestados a entender la ética como sinónimo de responsabilidad. Estos resultados, a pesar de ser extraídos de una muestra de 170 encuestados compuesta por trabajadores contratados, empleados y obreros fijos y personal suplente, están en concordancia con lo expresado por González (2000), quien sostiene que la responsabilidad en la ética coincide con el momento en el que hablamos de moralizar las actividades sociales, refiriéndonos con eso a los diversos mecanismos o estrategias que cada una de estas actividades incorpora para lograr las metas sociales.

Podemos ver entonces que la ética empresarial es una disciplina emergente en el campo de estudio de las organizaciones. Se encuentra influida por las representaciones sociales de los actores que integran los diversos espacios públicos y privados, así como por el contexto global en el cual influyen factores económicos, las tendencias mundiales y las exigencias de una colectividad que la demanda como proceso rector en las prácticas organizacionales.

Las representaciones sociales, en tanto proceso social, sólo pueden aparecer en grupos y sociedades en las que el discurso social incluye la comunicación. Estas sociedades heterodoxas incluyen y aceptan la posibilidad de opinión pública. Es esta experiencia y conocimiento contradictorio lo que permite el tipo de discurso colectivo que crea, en las sociedades modernas, lo que llamamos conocimiento ordinario y sentido común. En el proceso de conversación y en los medios de comunicación de masas, los objetos sociales son creados y elaborados por actores sociales que pueden tomar parte en el proceso de comunicación mediante cualquiera de los medios que posean. En este sentido no se tienen antecedentes sobre el estudio de las representaciones sociales referidas a la ética empresarial en el contexto latinoamericano. 
Para efectos de este trabajo se supera la concepción de las representaciones sociales como diferentes a otros procesos psicológicos, tales como las actitudes que tienen un elemento cognitivo, social, conductual y que se caracterizan por ser individuales. Así Moscovici (1996) expresa que no deben ser fenómenos opuestos sino que "el concepto de actitud es parte de una de las dimensiones de las RS" (p. 124). El presente estudio tiene como interés develar las representaciones sociales de la ética empresarial en el contexto latinoamericano, específicamente aquellas que emergen del imaginario de los actores que se desenvuelven en el medio organizacional venezolano. Las representaciones sociales se elaboran y naturalizan a través de la objetivación. En este orden de ideas, Abric (2001) señala que al "identificar los elementos constitutivos de la representación sobre ética empresarial se logra conocer la organización de estos elementos e identificar el núcleo central de la representación" (p.20-21). De acuerdo a estas consideraciones, las preguntas que guían esta investigación son: ¿Cuáles son las representaciones sociales relacionadas con la ética empresarial que se encuentran en el imaginario de los empresarios venezolanos? ¿Cuál es la noción de ética empresarial que emerge en la cotidianidad de las empresas en Venezuela? ¿De qué manera los problemas éticos de la sociedad están asociados a los comportamientos y prácticas en el ámbito empresarial venezolano?

Con el fin de responder estas preguntas, la investigación asumió como objetivo general de estudio tratar de comprender las representaciones sociales de la ética empresarial como proceso social construidas por una comunidad de empresarios venezolanos. Bajo esta meta general, se asumieron como objetivos específicos: 1. Analizar la noción de ética empresarial como representación social que emerge en la cotidianidad de los actores que intervienen en la investigación en el caso venezolano. 2. Determinar las creencias como representaciones sociales relacionadas con la ética empresarial desde el imaginario de los empresarios venezolanos. 3. Interpretar las representaciones sociales sobre los problemas éticos asociados al comportamiento y práctica en el ámbito empresarial venezolano.

\section{Revisión de la literatura}

La representación social es un modelo interno que tiene por función conceptualizar lo real a partir del conocimiento previo, designar una forma específica de conocimiento: «el saber de sentido común» en el que el contenido significa una forma particular de pensamiento social (Moscovici, 1984). Por consiguiente, las representaciones sociales son tipos de creencias paradigmáticas, organizaciones de creencias, organizaciones de conocimiento y lenguajes, y las 
encontramos en distintas estructuras de conocimiento (Moscovici y Marková 2003).

Moscovici (1973) define a las representaciones sociales como un sistema de valores, ideas y prácticas que tienen una doble función: en primer lugar, establecer un orden que permita a los individuos orientarse en su mundo social y material y dominarlo y, en segundo término, permitir la comunicación entre los miembros de una comunidad, aportándoles un código para el intercambio social y un código para denominar y clasificar de manera inequívoca los distintos aspectos de su mundo y de su historia individual y grupal. Moscovici (1998) plantea cuatro elementos constitutivos de estas representaciones: la información, que se relaciona con lo que "yo sé"; la imagen, que se relaciona con lo que "veo"; las opiniones, relacionadas con lo que "creo" y las actitudes con lo que "siento". Estos elementos se toman como guía para el análisis de la información. La representación es una acción psicológica que posee una función simbólica, ya que implícitamente contiene un significado y éste tiene que ver directamente con la situación del sujeto frente al mundo en que vive y con el que se relaciona. En resumen para Moscovici, las representaciones sociales son una organización psicológica, una modalidad de conciencia particular, que posee las siguientes características: la normatividad legítima, es decir, el deber ser en cuanto la fijación de los límites y el bien como parte de lo deseable, como lo que nos hace posible desear; la externalidad, que hace referencia a elementos antes y más allá de las manifestaciones individuales, como elementos que permanecen y permiten ordenar el mundo (un ejemplo son las creencias y prácticas religiosas como hechos que anteceden a los seres humanos); la intersubjetividad, como elemento de las representaciones colectivas, en tanto que acervo de conocimientos y memoria colectiva, es el conocimiento compartido que en nuestro caso son las representaciones sociales sobre el fenómeno estudiado.

Las representaciones sociales, en tanto que producto, se caracterizan por ser elaboradas mediante el discurso, el lenguaje y la comunicación, y se destaca el choque de ideas en la formación de nuevas representaciones sociales. Los procesos de las representaciones sociales son de carácter sociocognitivo, en los que las regulaciones sociales son inmanentes al funcionamiento cognitivo de las personas. Los procesos que describen el funcionamiento y la generación de representaciones sociales son la objetivación y el anclaje. Estos designan la actividad social y cognitiva que permite la construcción de conocimiento social compartido por los grupos sociales.

Como objetivación podemos definir al mecanismo que permite la concretización de lo abstracto, proceso fundamental en el conocimiento social. Se refiere a la trasformación de conceptos abstractos extraños en experiencias 
o materializaciones concretas. La objetivación en las representaciones sociales trae como consecuencia la producción del núcleo figurativo (Álvarez, 2002). Dicho elemento, también conocido como central o principio generador (Wagner y Elejabarrieta, 1999), tiene dos finalidades fundamentales: la primera de ellas implica una tarea productora de significado a través de la cual los demás componentes de una representación social adquieren o transforman el mismo; la segunda es la de organizar a todas las relaciones que traen como consecuencia la asociación de los elementos que componen a las representaciones sociales.

El proceso de anclaje, a su vez, permite incorporar lo extraño en una red de categorías y significaciones. Dos modalidades de intervención permiten describir el funcionamiento del anclaje: la inserción del objeto de representación en un marco de referencia conocido y preexistente y la instrumentalización social del objeto representado. Esto posibilita la inserción de las representaciones en la dinámica social, haciéndolas instrumentos útiles de comunicación y comprensión. Las representaciones sociales se convierten en sistemas de lectura de la realidad social, expresando y contribuyendo a desarrollar los valores sociales existentes. Por otra parte, en tanto que sistema de representación, el anclaje posibilita que las personas puedan comunicarse en los grupos a que pertenecen bajo criterios comunes, con un mismo lenguaje para comprender los acontecimientos, las personas $\mathrm{u}$ otros grupos.

Abric (2001) sugiere que toda representación está organizada alrededor de un núcleo central y de unos elementos periféricos. El núcleo central (principio generador) tiene dos funciones esenciales: una función generadora, mediante la cual los otros elementos de la representación adquieren o trasforman su significado, y una función organizadora de las relaciones que asocia los elementos de la representación. El núcleo central es coherente, expresa consenso y está considerablemente influido por la memoria colectiva del grupo. Este núcleo es la parte más estable, coherente y rígida de la representación, tiene una función consensual y define la homogeneidad compartida por el grupo, estableciendo un carácter normativo de las significaciones. Los elementos periféricos, además de proteger la estabilidad del núcleo central, tienen unas funciones que son fundamentalmente adaptativas, son mucho más sensibles al contexto que el núcleo central, conducen a la asimilación de situaciones específicas y permite integrar las experiencias individuales. Abric ha sugerido tres formas de posibles trasformaciones de una representación social en función de la magnitud de impacto que causen las prácticas contradictorias: 1. Transformación lenta: corresponde a las situaciones en las que las prácticas contradictorias generan esquemas extraños de comportamiento, resistiéndose a la trasformación, el núcleo se protege a través de esquemas periféricos, pero estos esquemas se ven 
ellos mismos afectados y se convierten en extraños. 2. Trasformación progresiva: las nuevas prácticas no son totalmente contradictorias con la representación y, por tanto, los esquemas activados pueden modificar la representación sin escisión o ruptura del núcleo. 3. Trasformaciones brutales: sucede cuando las prácticas contradictorias llegan a afectar directamente la significación del núcleo central. Hasta ahora solo han podido ser hipotetizadas.

\section{Consideraciones metódológicas presentes en la investigación}

En este estudio se asume que la realidad donde se produce la práctica empresarial es multireferencial e inestable como producto de la interrelación entre la diversidad de eventos que intervienen en el quehacer de las empresas venezolanas. Por consiguiente, el estudio se fundamentó en el paradigma interpretativo, donde la indagación y la comprobación de las evidencias se establecen a partir de los interrogantes e interpretaciones de los investigadores con los actores de la cotidianidad. En este contexto se admite la existencia de múltiples subjetividades y se reconoce que las empresas se constituyen como una fuerza organizacional que surge de las interrelaciones entre las partes o eventos, permitiendo que éstas se consoliden y subsistan. De esta manera, la investigación apuntala a reconocer a las empresas desde una perspectiva compleja, donde los elementos de "organización", "sistema" e "interrelación" son productos de las acciones y relaciones que emergen del dinamismo de la actividad empresarial.

$\mathrm{Al}$ asumir en esta investigación la realidad de manera multireferencial y cambiante, donde las explicaciones son un producto social y humano como consecuencia del posicionamiento epistemológico, metodológico y ontológico, los actores han ocupado un lugar determinante en la pesquisa. Sólo a través de ellos se logró comprender las representaciones sociales de la ética empresarial desde la cotidianidad, a partir de los testimonios de los profesionales y por las nociones teóricas que conforman los tipos de estructura de conocimiento.

La estrategia de investigación se focalizó de acuerdo a lo postulado por Abric (1992), quien manifiesta que el acercamiento a las RS debe ser plurimetodológico debido a su complejidad. Se utilizaron los siguientes métodos: el cuestionario para el paradigma tradicional y entrevistas para el interpretativo. La muestra fue integrada, de manera intencional, por 16 gerentes de diferentes instituciones privadas, asegurándose que las características de los entrevistados constituyeran el grupo de informantes clave dada la naturaleza de la investigación y que proporcionaran la mayor información significativa en la descripción e interpretación del fenómeno estudiado. El cuestionario permitió obtener información relativa a los principales problemas éticos percibidos por los gerentes encuestados. La intención de la guía 
de entrevistas fue obtener información sobre la realidad de estudio en el primer semestre del año 2008 en la ciudad de Caracas.

En los discursos recopilados en la guia de entrevista no estructurada se obtuvieron una serie de categorías en los contenidos, así como conexiones importantes en las significaciones que los informantes clave expresaron sobre la ética empresarial. Por una parte, las categorías emergentes, producto del proceso de saturación, se elaboraron y se integraron. Este proceso de categorización se inició con la recolección de los datos, especialmente la transformación de los datos descriptivos en datos interpretativos y analiticos. Según Martínez (2000), este proceso consiste en clasificar las partes en relación con el todo, de asignar categorías o clases significativas, de ir constantemente diseńando y rediseñando, integrando y reintegrando el todo y las partes durante el análisis del material. Categorizar estaría relacionado con clarificar, conceptualizar o codificar, mediante un término o expresión que sea claro o inequívoco (categoría descriptiva) el contenido o idea central de cada unidad temática.

En este sentido se hizo necesario definir y explicar el significado que los protagonistas le otorgaron a la ética empresarial desde su propia perspectiva. Posteriormente se procedió a organizar la información de acuerdo con las categorías identificadas, a fin de iniciar el análisis articulado de la información, relacionando los elementos de la categorización con las tendencias identificadas para lograr comprensión integral de las significaciones imaginarias detectadas, ejercicio que permitió mostrar un cuerpo de representaciones sociales sobre la ética empresarial. Este enfoque de las representaciones sociales ha permitido, de acuerdo a Parra (2001), "abordar la realidad social desde la complejidad, en cuanto se resuelven las paradojas de lo permanente y lo dinámico, lo cuantitativo y lo cualitativo, el individuo y el grupo" (p. 35).

En la investigación también se incorporó como recurso metodológico la complementariedad (Bericat, 1998), para integrar los hallazgos provenientes de las entrevistas (discurso abierto y espontáneo) y los resultados obtenidos en la encuesta que permitieron cuantificar los problemas éticos que veían los informantes claves, desde diferentes perspectivas, como una variante en el estudio en el tema de las representaciones sociales. Las respuestas fueron jerarquizadas de acuerdo a las frecuencias obtenidas (ver Cuadro 1).

\section{Resultados de la investigación}

El análisis de la conceptualización de la noción de ética develada en el estudio se orientó a una conceptualización de la ética que trasciende del ámbito organizacional al entorno social y laboral. Este hallazgo concuerda con el 
planteamiento de Cortina (2004) en su consideración de la organización como una "institución económica que tiene una responsabilidad moral con la sociedad, es decir con los consumidores, accionistas y empleados y proveedores" (p. 81). En otras palabras, la ética no es sólo individual, sino también corporativa y comunitaria.

El estudio demostró que en el imaginario de los empresarios venezolanos están presentes tres representaciones sociales: responsabilidad, solidaridad y honestidad. Estas se organizan alrededor de un núcleo central como principio generador: el altruismo desde la perspectiva de Morin (2006). Este núcleo manifiesta una función consensual que define la homogeneidad del grupo al establecer un carácter normativo al significado de la ética empresarial en las organizaciones venezolanas. En este sentido, tal como se presenta en la fig. 1, se observó que la representación social de la ética empresarial en el contexto venezolano es producto del conjunto de conceptos y afirmaciones referidas a "lo que sé" y a "lo que creo", mientras que los actores "ven" en el contexto venezolano de la cotidianidad empresarial conductas que fueron categorizadas como corrupción, conductas disfuncionales de los actores, falta de institucionalidad, poca responsabilidad con la comunidad y ausencia de criterios de calidad como las referidas, entre las principales conductas observadas. Figura 1: Representaciones sociales de la ética empresarial en el
contexto venezolano

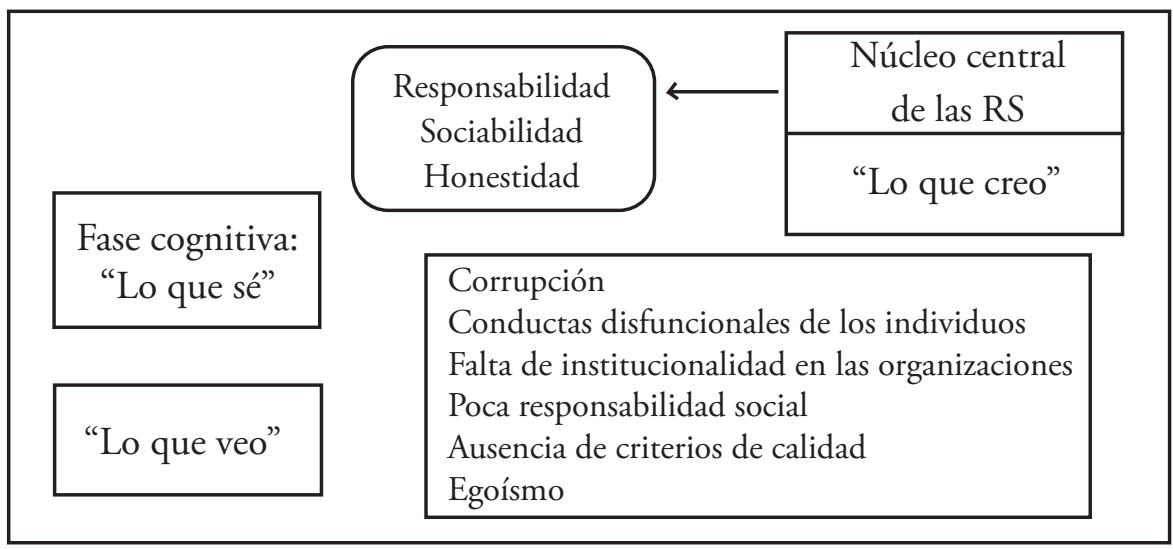

Como conductas disfuncionales fueron señaladas: irresponsabilidad, aplicación de la usura en los negocios, malversación de fondos en cuanto a desviación del dinero, carencia de principios éticos sólidos por parte del recurso 
humano, ausencia del valor de éxito, realización de la actividad sólo en base al principio monetarista, motivaciones en función de intereses económicos por encima de la calidad de vida y del medio ambiente, indiferencia social que genera falta de compromiso, competencia desleal, desorden y desconfianza, injerencia desproporcionada de la influencia y de los aspectos afiliativos y personales por encima de los criterios de éxito. Estos aspectos son coincidentes con los expuestos por Cova y Hannot (1995) sobre la conducta de los funcionarios públicos como el resultado de relaciones entre grupos, alianzas y conflictos, orígenes profesionales y sociales que caracterizan la cultura, a través de tradiciones, normas informales y hasta una visión de las cosas propia del "funcionario" público.

Otro hallazgo de la investigación, producto del uso de la complementariedad como método, permitió jerarquizar los principales problemas presentes en el imaginario de los entrevistados, los cuales se presentan en el Cuadro 1.

\section{Cuadro 1: Principales problemas éticos, señalados por los gerentes, asociados a las representaciones sociales.}

\begin{tabular}{|l|c|c|}
\hline Problemas éticos & Frecuencia & \% \\
\hline Corrupción & 17 & 41 \\
\hline $\begin{array}{l}\text { Conductas disfuncionales de } \\
\text { los individuos }\end{array}$ & 11 & 26 \\
\hline $\begin{array}{l}\text { Falta de instucionalidad de } \\
\text { las organizaciones }\end{array}$ & 7 & 17 \\
\hline Poca responsabilidad social & 6 & 114 \\
\hline $\begin{array}{l}\text { Ausencia de criterios de } \\
\text { calidad }\end{array}$ & 1 & 2 \\
\hline Total & $\mathbf{4 2}$ & $\mathbf{1 0 0}$ \\
\hline
\end{tabular}

El proceso de objetivación de las representaciones sociales sobre la ética empresarial en Venezuela explica cómo las conductas éticas disfuncionales son del dominio público, lo cual permite afirmar que existe un anclaje manifiesto. Las figuras del núcleo central están cargadas de significados, que son utilizadas para interpretar las conductas éticas y disfuncionales presentes en el medio empresarial venezolano. En este caso se evidenciaron los procesos de acuerdo a las bases propuestas por Moscovici (1970), según las cuales la objetivación pasa la ética al dominio del ser, mientras que el anclaje lo delimita en el hacer expresado. El anclaje, como representación social, entra en el dominio de lo familiar, asumiendo que este proceso está mediado por las actitudes y valores 
que los actores que participaron en el estudio reflejan como núcleo central de la representación de la ética empresarial y que se evidencia en las representaciones sociales de los actores externos.

\section{Conclusiones}

En síntesis, la interpretación de la representación social de la ética empresarial en el contexto venezolano es producto de los conceptos, afirmaciones y percepciones que emergieron de los actores en la cotidianidad de la práctica empresarial. En este sentido, la representación social de la ética empresarial está soportada por una concepción de "lo que sé" y de "lo que creo". En cuanto a las percepciones de los problemas éticos se siguen las ideas de Jodelet (2004), quien señala que las representaciones sociales más fuertes dentro de la sociedad aparecen con un planteamiento de creencias a través de la noción de agrupación de los sujetos en su pensamiento como una realidad actual de las sociedades.

Este estudio sobre representaciones sociales agrega información en cuanto al anclaje, mediante el cual lo no familiar o remoto es asimilado en las categorías de la cognición cotidiana y la objetivación que hace que las representaciones se proyecten en el mundo. Así, lo que está a nivel de ideas se transforma en concreto. En este "acercamiento", a través del uso de métodos complementarios, la representación social sobre la ética empresarial engloba conceptos cognitivos, actitudes y valores, que en muchos trabajos, de acuerdo al enfoque de investigación usado, son tratados en forma individual. El uso de la teoría de las representaciones sociales permite la comprensión de un evento que está en el colectivo de una sociedad: la representación social de la ética empresarial.

El núcleo central derivado de este estudio es coherente, expresa consenso y está considerablemente influido por la acción colectiva del grupo y concuerda con los resultados de estudios previos realizados sobre la corrupción en Venezuela. ${ }^{1}$ En estudios posteriores es necesario explorar la posible interdependencia entre representaciones sociales y el lenguaje como una forma de transformar la praxis social. 


\section{Bibliografía}

-Abric, J.C (2001) Prácticas sociales y representaciones: México, Ediciones Coyoacán.

-Bericat, E. (1998), La integración de los métodos cuantitativo y cualitativo en la investigación social: Significado y medida. Barcelona: Editorial Ariel, S.A.

-Bonilla, E. y Rodríguez, P. (2005), Más allá del dilema de los métodos: La investigación en ciencias sociales. Bogotá: Grupo Editorial Norma, S.A.

-Borjas, L. y Rosales (2005), Inversión social empresarial y su aporte al desarrollo socioeconómico. Caso Proyecto Alcatraz de la C.A. Ron Santa Teresa. Trabajo presentado el Foro de responsabilidad Social, Caracas, V Congreso de investigación y Creación Intelectual. Universidad Metropolitana, del 15 al 18 de mayo de 2006.

-Cortina, A. (2005), Ética en la empresa. Madrid, Edic. Trotta. Séptima edición.

-Cova, A. y T. Hannot (1995), "La Administración Pública: Otra forma de ver a una villana incomprendida”, en: Naim, M. y R. Piñango, El caso Venezuela (Comps), pp. 258-286, Caracas, Ediciones IESA.

-Ferrer, J., Clemenza C. y J. Vázquez (2000). "El problema ético en la industria metalúrgica y metalmecánica”, Revista Tendencias de la Facultad de Ciencias Económicas y Administrativas, Vol. 1. No.2, Noviembre de 2000, pp. 133-144. Universidad de Nariño.

-García Marza (2004), Ética empresarial del diálogo a la confianza, Madrid, Edic Trotta.

-Hernández, R, Silvestre, K y Álvarez (2007), "Enseñanza de la ética en la formación gerencial”. Revista de Ciencias Sociales. [Online]. dez. vol.13, no.3 [citado 11 Setiembre 2008], p.531-536. Disponible en World Wide Web: <http://www.scielo. org.ve/scielo.php?script=sci_arttext $\&$ pid=S131595182007000300013\&lng=pt\&nrm =iso >. ISSN 1315-9518. 
-Jodelet, D. (2004), Vigencia de las representaciones sociales y su incidencia en las prácticas profesionales. Educar, Argentina. Disponible en portal.educ.ar/noticias/ entrevistas/dra-denise-jodelet-vigencia-de.php -58k-Consultado el mayo 2007

-Martínez, M. (2000), La investigación cualitativa etnográfica en educación (2a. ed.). Madrid: Ediciones Cátedra, Grupo Anaya, S.A.

-Martínez, Y. (2007), La ética en la praxis gerencial del sector salud. Caso: Corporación de salud del Estado Miranda, Caracas, Tesis presentada para optar al itulod e especialista en Gerencia Publica. Universidad Poltecnica de la Fuerza Armada Nacional

-Monasterios, D. (2003), "Modelo Teórico Demostrativo de la Corrupción como Condicionante del desarrollo Económico Social del un Pais (Caso: Venezuela)", Universidad Santa María caracas, Venezuela. Tesis para Optar al título de Doctor en Ciencias Económicas-Administrativos (Mención Honorífica y Publicación).

(2007), "Una apuesta para comprender la ética en la gerencia pública.” Ensayo y error, Año XVII, No 35, pp. 1-24.

-Moscovici, S. (1973), Prólogo a C. Herzlich, Health and Illnesss. Londres, Academic Press

(1984), "The phenomenon of social representations", en

-R.M. Farr y S. Moscovici (comp.), Social Representations, Cambridge, Cambridge University Press, pp. 3 - 69.

(1986), Psicology Social (2 Vols), Barcelona, Paidos

(1996), Social Representations and Pragmatic Communication, Social Sciencie Information, 33, pp. 163-177.

(1998), The history and actuality of social representations, en L.Flick (comp.), The psychology of the social. Cambridge, Cambridge University Press 
-Moscovici, S. y I. Marková (2003), "La presentación de las Representaciones Sociales: diálogo con Serge Moscovici”, en: Castorina, J. (Comp.) Representaciones sociales. Problemas teóricos y conocimientos infantiles. Edit. Gedisa.

-Morin, E. (2006) , El método 6, Madrid,Plaza ediciones

-Parra, M. (2001), "La Teoría de las representaciones Sociales. Reflexiones en torno a una experiencia de investigación," Fermentum, Mérida, Venezuela, año 11 No 30, enero-abril, 2001.

-Spence, L. (2000), Is Europe Distinctive from America? An Overview of Business Ethics in Europe School of Business and Management, Brunel University, Middlesex, UB8 3PH, UK. Paper for the ISBEE Conference, Brazil 2000.

-Taylor, S. y Bogdan, R. (1986), Introducción a los métodos cualitativos: Manual práctico teórico. México: Editorial Trillas, S.A. de C.V. 